\title{
Review Article \\ Pharmacotherapy of Chronic Obstructive Pulmonary Disease: A Clinical Review
}

\author{
Balazs Antus ${ }^{1,2}$ \\ ${ }^{1}$ Department of Pathophysiology, National Koranyi Institute of TB and Pulmonology, Piheno ut 1, Budapest 1121, Hungary \\ ${ }^{2}$ Department of Pulmonology, National Koranyi Institute of TB and Pulmonology, Piheno ut 1, Budapest 1121, Hungary
}

Correspondence should be addressed to Balazs Antus; antusb@hotmail.com

Received 11 January 2013; Accepted 7 February 2013

Academic Editors: A. Celi, A. Kurdowska, A. Miyazato, and A. Yokoyama

Copyright (C) 2013 Balazs Antus. This is an open access article distributed under the Creative Commons Attribution License, which permits unrestricted use, distribution, and reproduction in any medium, provided the original work is properly cited.

\begin{abstract}
Chronic obstructive pulmonary disease (COPD) is one of the leading causes of mortality and morbidity worldwide. In addition to generating high healthcare costs, COPD imposes a significant burden in terms of disability and impaired quality of life. Unlike many leading causes of death and disability, COPD is projected to increase in many regions of the world as the frequency of smoking is rising and the population is aging. The pharmacological treatment of COPD includes bronchodilators to relax smooth muscle, such as $\beta_{2}$-agonists (salbutamol, terbutaline, and fenoterol, short-acting $\beta_{2}$-agonists as well as salmeterol, formoterol, and indacaterol, and long-acting $\beta_{2}$-agonists) and anticholinergics, such as ipratropium, oxitropium (short-acting anticholinergic), and tiotropium (long-acting anticholinergic). Although airway inflammation in COPD poorly responds to steroids, several inhaled corticosteroids (fluticasone, budesonide, and beclomethasone) are in use in combination with long-acting $\beta_{2}$-agonists. Other medications include theophylline (both a bronchodilator and a phosphodiesterase inhibitor) and the phosphodiesterase- 4 antagonists, such as roflumilast. Finally, a number of novel long-acting anticholinergics and $\beta_{2}$-agonists with once- or twice-daily profiles are in development and clinical testing.
\end{abstract}

\section{Introduction}

Chronic obstructive pulmonary disease (COPD) is a respiratory disease characterized by chronic airway inflammation, a decline in lung function over time, and progressive impairment in quality of life. The disease has relatively high prevalence rates worldwide (5-13\%) [1,2] and is mainly caused not only by the inhalation of noxious substances, predominantly cigarette smoking in the Western world, but also by indoor air pollution, particularly in the developing countries.

COPD is associated with high mortality and morbidity rates and a high economic and social burden, mainly due to the requirement for substantial and ongoing medical support $[3,4]$. COPD is the fourth leading cause of death worldwide and is expected to be the third leading cause by 2030 [5]. It is generally believed that despite the availability of both national and international guidelines, COPD remains substantially underdiagnosed and undertreated and is rarely regarded as a health issue of top priority.

For many years, smoking cessation has been known to be the single effective intervention for reducing the risk of developing COPD and slowing its progression down [6]. However, recent data from long-term trials have shown that initiating maintenance pharmacological treatment at early stages of the disease, when there is an opportunity to alter the progression of the disease and maximize patient benefit, may alter the clinical course of COPD and can be more effective than at later stages of the disease $[7,8]$. Moreover, it has been demonstrated that despite the relative steroid insensitivity of airway inflammation in COPD, the combination of long-acting bronchodilator therapy with inhaled glucocorticosteroids (ICS) is beneficial for patients with severe COPD $[9,10]$. Thus, early and optimal pharmacotherapy appears to be fundamental in the management of COPD. 
The aim of this paper is to summarize briefly the pharmacotherapy of stable COPD and to give an overview of the pharmacological profile of these medications.

\section{Overview of Pharmacological Treatment in COPD}

In stable COPD pharmacotherapy is used to relieve symptoms, reduce the frequency and severity of acute exacerbations, reduce disease progression and mortality, and improve health status and increase exercise tolerance.

Previously, it has been conceptualized that COPD treatment should follow a stepwise approach, depending exclusively on disease severity as assessed by spirometry. Initially in mild (stage I) COPD, active risk reduction should be pursued with the addition of short-acting bronchodilators asneeded. As the disease progresses and lung function declines (stage II-IV) regular (maintenance) treatment with one or more long-acting bronchodilators, such as a long-acting muscarinic antagonist (LAMA; also known as a long-acting anticholinergic) or long-acting $\beta_{2}$-agonist (LABA), should be introduced alone or in combination with ICS.

More recently, data about the clinical presentation of COPD have resulted in a new classification of the disease. As highlighted in the latest version of the GOLD document, airflow limitation $\left(\mathrm{FEV}_{1}\right)$ alone is a poor descriptor of the disease status, and therefore the degree of airflow limitation has been amended by symptoms and exacerbation rate [11]. Four categories (A-D) have been established in which patients can be enrolled based on symptoms' scores and exacerbation history. Moreover, a model for initial pharmacological management has been proposed for each category allowing a more individualized treatment option for each subject.

Beside the medications mentioned above, a number of other agents are used in the management of COPD, including mucolytics and methylxanthines. Nonetheless, most guidelines do not currently recommend the widespread use of these agents. Finally, it should be noted that each treatment regimen needs to be patient-specific, especially in older people where severe comorbidities are more common.

The method of delivery is an important factor in the prescription of all medications in COPD. In general, inhaled therapy is preferred. For theophyllines, which are given orally, blood levels should be frequently checked as a result of the higher incidence of adverse effects which occur by the use of the oral route.

A variety of inhaler devices are available, and the delivery of the drug to the lung depends on devices and techniques. Dry powder inhalers (DPIs) may be more convenient and possibly provide improved drug deposition in COPD patients when compared with simple metered-dose inhalers (MDI) [12]. Nonetheless, the issue is somewhat controversial, and deposition depends also on the available inspiratory flow (acceleration) depending on the severity of COPD. Nebulizer solutions, on the other hand, may be better for those who are severely overinflated and consequently may have low inspiratory flow rates. There is evidence that a significant proportion of patients have problems with inhaler technique [13], and therefore, the prescribing physician must ensure that the patient is taught how to use the prescribed device and that their technique is checked periodically.

\section{Bronchodilators}

Medications that increase the forced expiratory volume in $1 \mathrm{sec}\left(\mathrm{FEV}_{1}\right)$ or improve other spirometric parameters, usually by altering airway smooth muscle tone, are termed bronchodilators. The use of bronchodilators is one of the key elements in the treatment of COPD, although there is often limited reversibility of airflow obstruction. Nevertheless, the regular use of bronchodilators significantly contributes to many other goals of treatment (see above), especially to symptoms' relieve and improvement of health-related quality of life.

Three types of bronchodilator are in common clinical use: (1) $\beta$-adrenoceptor agonists, (2) anticholinergic drugs, and (3) methylxantines. Bronchodilators are given either on an as-needed basis or on a regular basis. There is evidence that regular treatment with long-acting bronchodilators is more effective and convenient than treatment with short-acting agents.

3.1. $\beta_{2}$-Receptor Agonists. The principal action of $\beta_{2}$-receptor agonists is to relax airway smooth muscle by stimulating $\beta_{2}$ adrenergic receptors, which increases the intracellular concentration of cyclic adenosine monophosphate (cAMP) and activates protein kinase $\mathrm{A}$. In human airways, $\beta$-adrenergic receptors are all $\beta_{2}$-receptors. In asthma, $\beta_{2}$-agonists are the most effective bronchodilators available. In COPD the degree of functional reversibility in response to bronchodilators is variable. There is some evidence that patients, who respond better to $\beta_{2}$-agonists, may have more eosinophilic cells in their sputum and exhibit elevated fractional exhaled nitric oxide (FENO) concentration in exhaled breath [14]. These patients are often considered to have an "asthmatic" phenotype.

Short-acting inhaled $\beta_{2}$-agonists such as salbutamol, terbutaline, and fenoterol have a relatively rapid onset of bronchodilator effect, which usually wears off within 4-6 hours [15]. Salbutamol is almost 30 times as much selective for $\beta_{2}$ receptors as for $\beta_{1}$ [15]. Its $\mathrm{R}$-isomer is mainly responsive for bronchodilatation when used as an aerosol. Salbutamol is hydrolyzed in tissues and blood to yield the active compound, such as colterol. Over $70 \%$ of the inhaled drug is excreted in the urine within three days. Salbutamol is also accessible in tablets, as well as formulations for intramuscular and intravenous applications. Terbutaline is also relatively selective on $\beta_{2}$-receptors (such as on $\beta_{2}$-receptors of bronchial, vascular, and uterine smooth muscles). Terbutaline is also used intravenously to relax smooth muscles and inhibit uterine contractions. Finally, levalbuterol is another effective short-acting bronchodilator that can be applied in COPD patients. Salbutamol and levalbuterol are chemically identical except that they are different enantiomers. 
TABle 1: Mode of administration, chemical structure, lipophilicity $(\log P)$, and half time $\left(t_{1 / 2}\right)$ of $\beta_{2}$-receptor agonists.

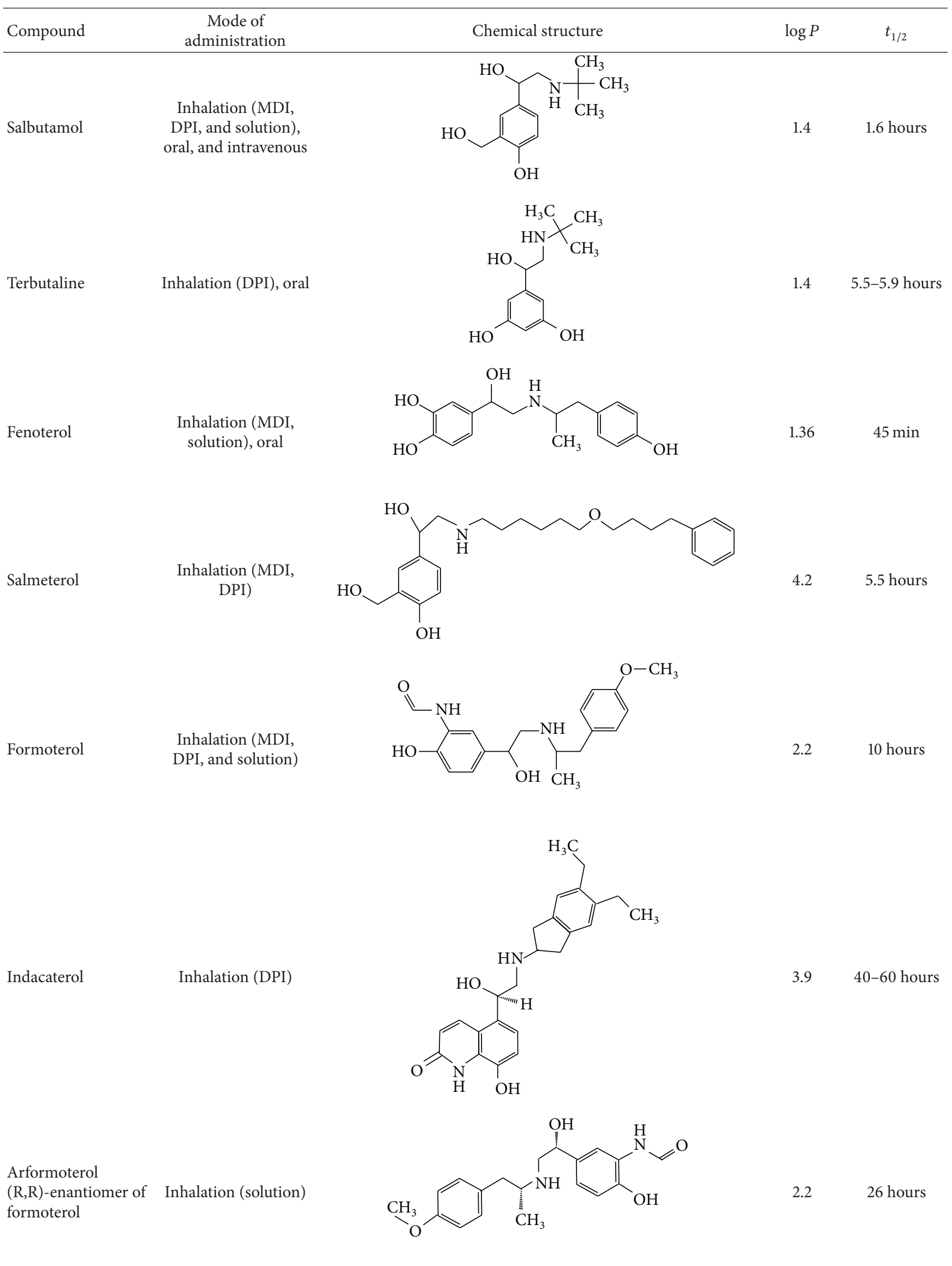


TABle 1: Continued.

\begin{tabular}{|c|c|c|c|c|}
\hline Compound & $\begin{array}{c}\text { Mode of } \\
\text { administration }\end{array}$ & Chemical structure & $\log P$ & $t_{1 / 2}$ \\
\hline Carmoterol & $\begin{array}{l}\text { Inhalation (MDI, } \\
\text { DPI) }\end{array}$ & & NA & 48 hours \\
\hline $\begin{array}{l}\text { Levalbuterol } \\
\text { (R,R)-enantiomer of } \\
\text { salbutamol }\end{array}$ & $\begin{array}{c}\text { Inhalation (MDI, } \\
\text { solution) }\end{array}$ & 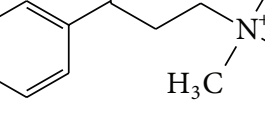 & 1.4 & 1.6 hours \\
\hline Vilanterol & $\begin{array}{c}\text { Inhalation (MDI, } \\
\text { DPI) }\end{array}$ & & 3.8 & NA \\
\hline
\end{tabular}

MDI: metered-dose inhaler, DPI: dry power inhaler.

LABAs such as salmeterol and formoterol are formulated for twice-daily dosing, have a duration of effect of 12 hours or more with no loss of effectiveness overnight or with regular use in COPD patients [16, 17]. These agents have been shown to reduce the need for rescue medication, improve symptoms and patient-related outcomes, and have a favorable safety profile $[18,19]$. Formoterol has a faster onset of action than salmeterol [20], which may be relevant to some patients, especially for morning symptoms. Arformoterol, the (R,R)enantiomer of formoterol, can be an effective alternative for patients who cannot use conventional inhaler devices, since this drug is available as a nebulized solution.

Salmeterol is not used to relieve a COPD attack that has already started [15]. As its dose is low, systemic level of salmeterol is either undetected or very low. A dose of about $12 \mu \mathrm{g}$ of formoterol has the effect of $50 \mu \mathrm{g}$ of salmeterol. Salmeterol is metabolized by cytochrome P450 3A4 to $\alpha$ hydroxysalmoterol, while formoterol is O-demethylated by various CYP enzymes (cytochrome P450 2D6, 2C9, and 2C19, 2A8). Finally, it should be noted that the disease-modifying properties of LABAs are still controversial. These agents improve lung functions, dyspnoea, health-related quality of life, and exacerbation rate but may have no effect on rate of decline in lung function and mortality.

Indacaterol, a novel $\beta_{2}$-agonist approved already by both the EMA and the FDA for the treatment of COPD, is currently the only once-daily LABA available for this disease. Since the lung function improvement achieved by indacaterol appears to be slightly better compared to other twice-daily LABAs [21], indacaterol could become a highly effective therapeutic option for the maintenance treatment of COPD.
Metabolism of indacaterol was hydroxylation on benzylic carbon, glucuronidation, and oxidative cleavage [15]. Mode of administration, chemical structure, lipophilicity $(\log P)$, and half time of elimination $\left(t_{1 / 2}\right)$ of $\beta_{2}$-receptor agonists are given in Table 1.

3.2. Anticholinergics. The most important effect of anticholinergic medications, such as ipratropium, tiotropium, and oxitropium bromide appears to be blockade of the action of acetylcholine on $\mathrm{M}_{3}$ receptors [22]. Current short-acting drugs also block $\mathrm{M}_{2}$ receptors and modify transmission at the preganglionic junction, although these effects may be less important in COPD. Ipratropium is probably the most frequently used short-acting anticholinergic drug at present. Although it improves lung function and quality of life of COPD patients, the rate of lung function decline, as a hallmark of COPD, may not be affected by ipratropium treatment [22]. In general, the bronchodilating effect of shortacting inhaled anticholinergics lasts longer than that of shortacting $\beta_{2}$-agonists, with some bronchodilating effect lasting up to 8 hours after administration.

Tiotropium is the only LAMA currently licensed for use in COPD [23]. Tiotropium has been formulated for once-daily dosing, providing 24-hour bronchodilation, and has a selectivity for $M_{1}$ and $M_{3}$ receptors. The clinical database for tiotropium has confirmed an excellent clinical profile for this agent, including symptom improvement, decreased hyperinflation, reduced dyspnea, and improved quality of life [24, 25]. Moreover, treatment with tiotropium reduces the frequency of exacerbations [26] and improves 
TABLE 2: Mode of administration, chemical structure, lipophilicity $(\log P)$, and half time $\left(t_{1 / 2}\right)$ of anticholinergics.

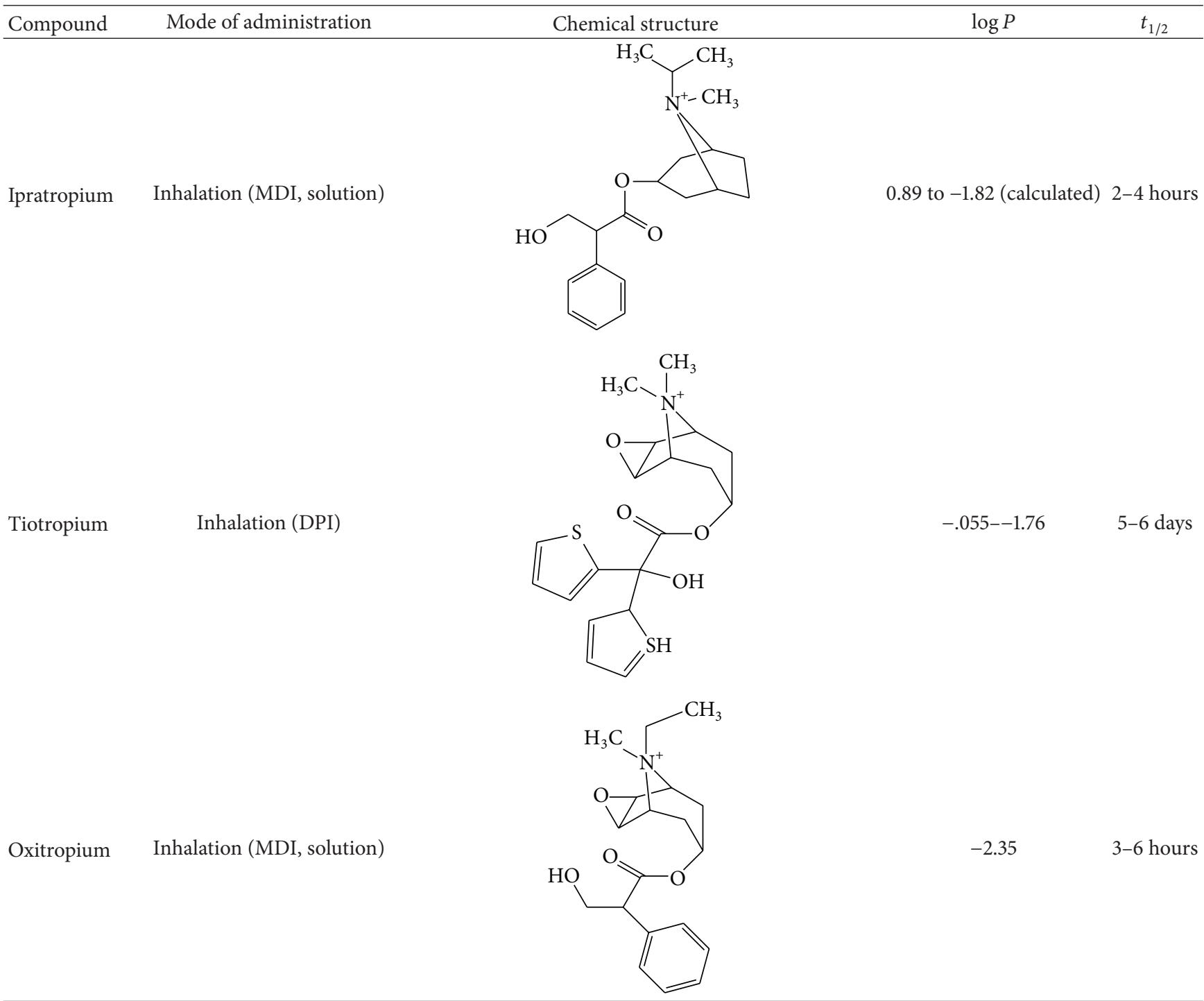

the effectiveness of pulmonary rehabilitation [27]. Therefore, tiotropium is generally recommended for the treatment of all symptomatic patients requiring maintenance treatment.

Nevertheless, in recent years some concerns have been raised about tiotropium's safety. In particular, disparate sources have identified stroke and cardiovascular events as possible adverse outcomes. In 2008, Singh et al. published a meta-analysis of 17 randomized clinical trials evaluating the cardiovascular risk associated with inhaled anticholinergic agents [28]. Authors concluded that the use of these drugs was associated with a significantly increased risk of major adverse cardiovascular events, including death from cardiovascular causes, myocardial infarction, and stroke. In contrast, the UPLIFT trial did not show an increased risk of myocardial infarction, death from cardiovascular causes, or death from any cause in its comparison of tiotropium with placebo [29]. Disparate results were then discussed in several forums. Finally, the FDA concluded that because of the strength of the UPLIFT data, the absence of strong signal related to stroke or cardiovascular events with tiotropium, and the potential methodological limitations of the meta-analysis of Singh et al. [28], the current data do not support the assumption of increased risk of stroke, heart attack, or death associated with tiotropium treatment [30].

Combining bronchodilators with different mechanisms and durations of action may increase the degree of bronchodilation for equivalent or lesser side effects. For example, a combination of a short-acting $\beta_{2}$-agonist and an anticholinergic produces greater and more sustained improvements in $\mathrm{FEV}_{1}$ than either drug alone [31]. Similarly, the addition of an LABA to an LAMA has been shown to be more effective than either agent alone, without increased side effects [32] and is now included as an option for patients who fail in long-acting bronchodilator monotherapy in most guidelines.

After dry powder inhalation of tiotropium, urinary excretion is about $14 \%$ of the dose. The remaining dose is probably not absorbed. Mode of administration, chemical structure, $\log P$, and $t_{1 / 2}$ values of anticholinergics are given in Table 2 . 
TABLe 3: Mode of administration, chemical structure, lipophilicity $(\log P)$, and half time $\left(t_{1 / 2}\right)$ of methylxanthines.

\begin{tabular}{lclll}
\hline Compound $\quad$ Mode of administration & Oog $P$ & $t_{1 / 2}$ \\
Theophylline $\quad$ Oral, intravenous & & \\
\hline
\end{tabular}

3.3. Methylxanthines. Methylxanthines may act as nonselective phosphodiesterase (PDE) inhibitors but have been reported to have a range of nonbronchodilating actions that may be potentially beneficial [33]. For example, changes in respiratory muscle function have been reported in patients treated with theophylline [34], but whether this reflects changes in dynamic lung volumes or a primary effect on the muscle remains unclear. Similarly, methylxanthines may improve arterial blood gas tension and ventilatory capacity. Moreover, there is evidence that theophylline at low therapeutic concentrations is an activator of histone deacetylases, and that this activation enhances the anti-inflammatory effect of corticosteroids [35]. Oral low-dose theophylline can reduce exacerbation rates in COPD patients but offers minimal benefits in terms of lung function [36]. By contrast, highdose theophylline is an effective bronchodilator. Nonetheless, other long-acting bronchodilators are preferred because of toxicities associated with high-dose theophylline such as headache, insomnia, nausea and heartburn and potentially life-threatening atrial and ventricular arrhythmias and grand mal convulsions.

Theophylline is metabolized to 1-methylxanthine, 3methylxanthine (CYP250 1A2), and 1,3-dimethyluric acid, as well as to caffeine through $\mathrm{N}$-methylation. Caffeine and 3methylxanthine are pharmacologically active metabolites of theophylline [15]. Mode of administration, chemical structure, $\log P$, and $t_{1 / 2}$ values of theophylline are given in Table 3.

\section{Glucocorticosteroids}

In asthma, treatment with corticosteroids results in reduction in airway inflammation and sputum eosinophilia and a simultaneous improvement in clinical symptoms. By contrast, in COPD the response to steroids is likely to be poor. Therefore, the routine use of ICS, for example, fluticasone, budesonide, or beclomethasone is not recommended as monotherapy in COPD in the existing guidelines.

However, ICS agents may have complimentary effects when added to a LABA. Accordingly, there is evidence that an ICS combined with a LABA is more effective than the individual components in reducing exacerbations and improving lung function and health status [37, 38]. Adding ICS to a LABA is usually recommended for patients with severe or very severe COPD (stages III and IV) who have repeated exacerbations [11]. Nonetheless, caution may be required in some patients, since combination therapy may increase the likelihood of pneumonia [7, 26, 39].

Triple therapy with a LAMA plus a LABA and an ICS may have further clinical benefits in patients with severe COPD. For example, tiotropium plus salmeterol and fluticasone produced greater improvement in bronchodilation, dyspnea, and rescue medication use than salmeterol and fluticasone, or tiotropium alone [40]. Similarly, the addition of budesonide plus formoterol to tiotropium improved lung function, reduced daytime and nighttime symptoms, and the rate of exacerbations [41]. Other rarely used ICSs in COPD include flunisolide, mometasone, and triamcinolone. Finally, it should be noted that although the main effect of ICS in COPD is the reduction of exacerbation frequency and drugs should be primarily prescribed for patients in the exacerbation phenotype, doctors in many countries often do not respect these considerations in real life practice.

Due to lack of efficacy, long-term treatment with oral glucocorticosteroids is not recommended in COPD. By contrast, many national guidelines recommend the use of a short course of oral glucocorticosteroids to identify COPD patients who might benefit from long-term treatment with ICS. Assessment of steroid responsiveness may also be important in patients with fixed airflow obstruction in whom neither history nor physiological measurements permits easy discrimination between asthma and COPD.

It is well known that systemic steroids may have numerous side effects (myopathy, diabetes, hypertension, etc.). Metabolism of fluticasone results in inactive fluticasone 17 $\beta$-carboxylic acid, and the metabolic step is catalyzed by cytochrome P450 3A (3A4, 3A5, and 3A7) enzymes. Similarly, budesonide is also metabolized mainly by CYP $3 \mathrm{~A} 4$ to hydroxylated products that do not have remarkable glucocorticoid activity. Beclomethasone is used in the form of its dipropionate, its metabolism is mediated by esterase enzymes to produce beclomethasone 17-monopropionate [15]. Mode of administration, chemical structure, $\log P$, and $t_{1 / 2}$ values of corticosteroids are given in Table 4.

\section{Emerging Treatment Options: New Bronchodilators}

PDE-4 inhibitors have anti-inflammatory activity that specifically targets cells commonly linked with airway inflammation and have been shown to reduce airway inflammation 
TABLE 4: Mode of administration, chemical structure, lipophilicity $(\log P)$, and half time $\left(t_{1 / 2}\right)$ of glucocorticosteroids.

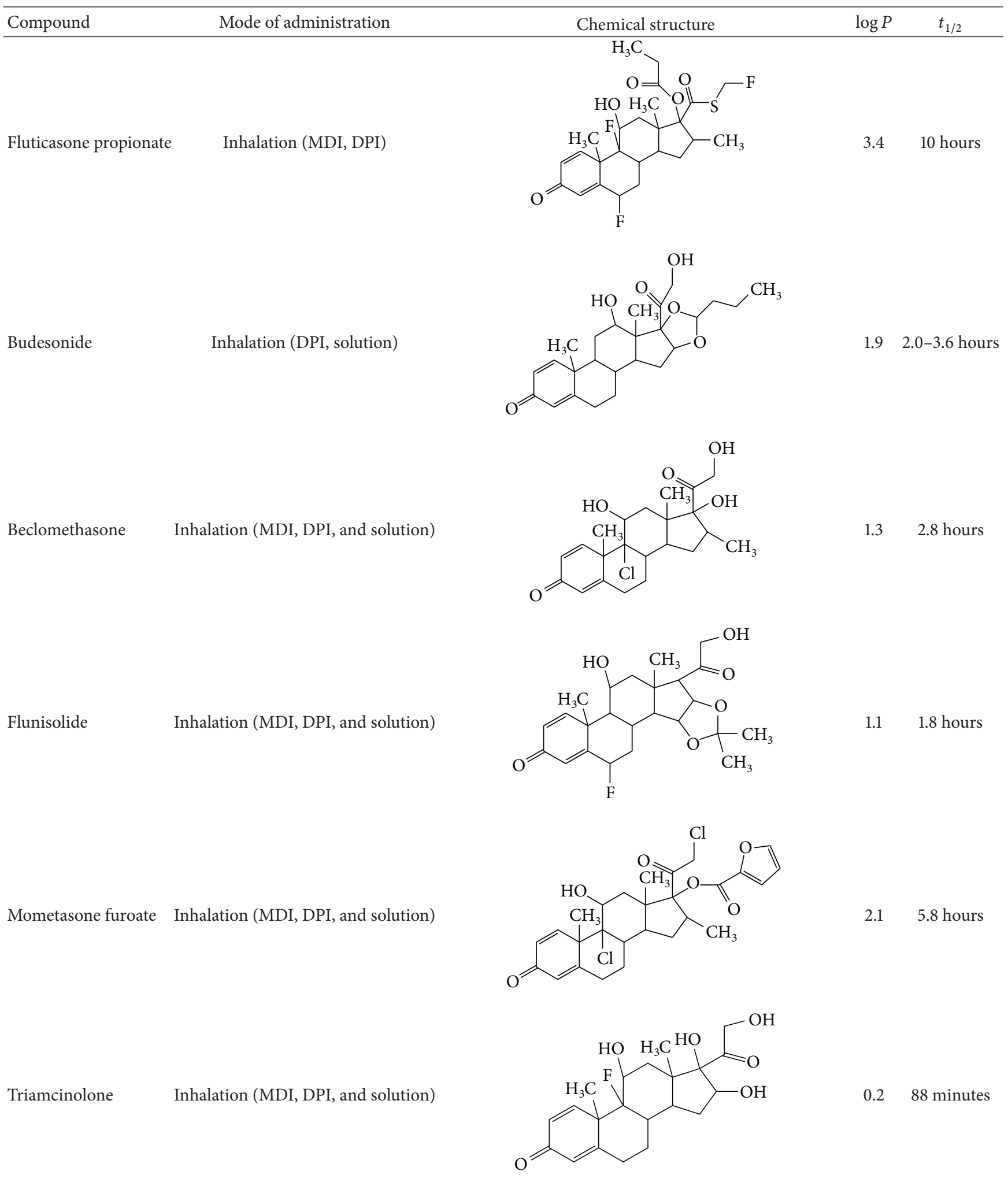


TABle 5: Mode of administration, chemical structure, lipophilicity $(\log P)$, and half time $\left(t_{1 / 2}\right)$ of PDE-4 inhibitors and anti-TNF- $\alpha$ drugs.

Compound Mode of administration

in preclinical and clinical studies [42]. Roflumilast, a oncedaily oral drug, is a selective PDE-4 inhibitor that has been approved for clinical use in some countries as addon therapy to bronchodilator treatment for severe to very severe COPD patients with a history of exacerbations [43] (Table 5). In the GOLD report [11], it is recommended that PDE-4 inhibitors should be given to group $\mathrm{C}$ patients as an alternative choice if the patient has chronic bronchitis. In group $\mathrm{D}$ patients, it is also possible to add PDE-4 inhibitors to the treatment of LAMA or ICS plus LABA. Roflumilast has been demonstrated to improve lung function and to reduce the rate of exacerbations and the requirement for anti-inflammatory/anti-infective medications and to improve quality of life $[44,45]$. However, the improvements in these variables may be moderate compared with inhaled bronchodilators such as tiotropium or salmeterol. Nausea, diarrhea, and weight loss are common side effects of PDE-4 inhibitors, which may limit the use of roflumilast in some patients.

Cilomilast is another orally active PDE-4 inhibitor that has been developed for the treatment of COPD (Table 5). The results of phase- 1 and phase- 2 studies have demonstrated that cilomilast significantly improves lung function and quality of life to a clinically meaningful extent [46]. In phase-3 studies, however, these beneficial effects of cilomilast were either not confirmed, or the achieved improvements in cilomilasttreated patients were minor $[47,48]$. Roflumilast is subjected to $\mathrm{N}$-oxidation during its metabolism, while cilomilast is metabolized by decyclopentylation, glucuronidation, and 3hydroxylation [15].

There are a number of novel LABAs including vilanterol trifenatate, carmoterol, and olodaterol with once-daily profiles in development $[49,50]$. The most clinically relevant and convincing data accumulated in COPD are available for vilanterol. It produces a rapid and prolonged bronchodilation over $24 \mathrm{~h}$ and is well tolerated with no clinically significant unwanted systemic effects [51]. In moderate to severe COPD patients, vilanterol in doses of 25 and $50 \mu \mathrm{g}$ once daily provides both statistically and clinically relevant 24-hour improvements in lung function compared with placebo [52]. Combination of vilanterol with umeclidinium, a new LAMA [53], or with fluticasone furoate [54] may represent further promising therapeutic options for patients with obstructive lung diseases. Finally, olodaterol appears to be also a promising long-acting $\beta_{2}$-adrenoceptor agonist, with bronchodilation maintained over $24 \mathrm{~h}$ that offers an opportunity for once-daily dosing in patients who require maintenance bronchodilator therapy for the management of COPD symptoms [55].

Currently, the only LAMA marketed for the treatment of COPD is tiotropium bromide (see above), but several others are in various stages of development, including aclidinium bromide $[56,57]$. In some countries, aclidinium bromide has been already marketed. Compared with other long-acting bronchodilators, including tiotropium bromide, aclidinium bromide leads to at least similar clinically important improvements in level of $\mathrm{FEV}_{1}$, health status, use of rescue medication, and day-time dyspnoea scores in patients suffering from moderate to severe COPD $[58,59]$. With twice-daily dosing, aclidinium bromide may have clinically important effect on night-time symptom scores in COPD patients, but further studies are needed in order to permit valid conclusions with regard to this point [60]. The effect of aclidinium bromide on exercise tolerance, as assessed by exercise endurance time and dynamic hyperinflation in COPD patients seems to be at least comparable to other long-acting bronchodilators, including tiotropium bromide, and indacaterol [61].

\section{Conclusions and Perspectives}

Since airway inflammation in COPD poorly responds to antiinflammatory agents available at present, sustained bronchodilation continues to be the major objective of COPD 
management. Increasing evidence suggests that initiation of long-acting bronchodilator treatment at an early stage of the disease can slow down disease progression and improve the patients' quality of life. Moreover, combining bronchodilators with different pharmacological profiles may further increase the efficiency of treatment. All these strategies should be applied to reduce further increases in the socioeconomic burden of COPD.

\section{Conflict of Interests}

The author declares no conflict of interests related to the publication of this paper.

\section{Acknowledgments}

The work was supported by the Hungarian Respiratory Foundation (MPA) and the Hungarian National Scientific Foundation (OTKA 83338). The author acknowledges the help of Professor Dr. Huba Kalasz (Semmelweis University, Department of Pharmacology and Pharmacotherapy, Budapest, Hungary) in paper preparation. Dr. B. Antus is a recipient of Bolyai Janos Scholarship of the Hungarian Academy of Sciences.

\section{References}

[1] A. D. Lopez, K. Shibuya, C. Rao et al., "Chronic obstructive pulmonary disease: current burden and future projections," European Respiratory Journal, vol. 27, no. 2, pp. 397-412, 2006.

[2] D. M. Mannino and A. S. Buist, "Global burden of COPD: risk factors, prevalence, and future trends," The Lancet, vol. 370, no. 9589, pp. 765-773, 2007.

[3] R. Nielsen, A. Johannessen, B. Benediktsdottir et al., "Present and future costs of COPD in Iceland and Norway: results from the BOLD study," European Respiratory Journal, vol. 34, no. 4, pp. 850-857, 2009.

[4] S. D. Sullivan, S. D. Ramsey, and T. A. Lee, "The economic burden of COPD," Chest, vol. 117, no. 2, 2000.

[5] C. D. Mathers and D. Loncar, "Projections of global mortality and burden of disease from 2002 to 2030," PLoS Medicine, vol. 3, no. 11, article e442, pp. 2011-2030, 2006.

[6] P. D. Scanlon, J. E. Connett, L. A. Waller et al., "Smoking cessation and lung function in mild-to-moderate chronic obstructive pulmonary disease: the lung health study," American Journal of Respiratory and Critical Care Medicine, vol. 161, no. 2, pp. 381390, 2000.

[7] P. M. A. Calverley, J. A. Anderson, B. Celli et al., "Salmeterol and fluticasone propionate and survival in chronic obstructive pulmonary disease," The New England Journal of Medicine, vol. 356, no. 8, pp. 775-789, 2007.

[8] M. Decramer, B. Celli, S. Kesten, T. Lystig, S. Mehra, and D. P. Tashkin, "Effect of tiotropium on outcomes in patients with moderate chronic obstructive pulmonary disease (UPLIFT): a prespecified subgroup analysis of a randomised controlled trial," The Lancet, vol. 374, no. 9696, pp. 1171-1178, 2009.

[9] M. Cazzola and R. Dahl, "Inhaled combination therapy with long-acting $\beta 2$-agonists and corticosteroids in stable COPD," Chest, vol. 126, no. 1, pp. 220-237, 2004.
[10] P. M. Calverley, W. Boonsawat, Z. Cseke, N. Zhong, S. Peterson, and H. Olsson, "Maintenance therapy with budesonide and formoterol in chronic obstructive pulmonary disease," European Respiratory Journal, vol. 22, no. 6, pp. 912-919, 2003.

[11] "Global strategy for the diagnosis, management, and prevention of chronic obstructive pulmonary disease," http://www .goldcopd.com/.

[12] B. P. Yawn, G. L. Colice, and R. Hodder, "Practical aspects of inhaler use in the management of chronic obstructive pulmonary disease in the primary care setting," International Journal of Chronic Obstructive Pulmonary Disease, vol. 7, pp. 495-502, 2012.

[13] R. A. M. Al-Showair, W. Y. Tarsin, K. H. Assi, S. B. Pearson, and H. Chrystyn, "Can all patients with COPD use the correct inhalation flow with all inhalers and does training help?" Respiratory Medicine, vol. 101, no. 11, pp. 2395-2401, 2007.

[14] A. Papi, M. Romagnoli, S. Baraldo et al., "Partial reversibility of airflow limitation and increased exhaled NO and sputum eosinophilia in chronic obstructive pulmonary disease," American Journal of Respiratory and Critical Care Medicine, vol. 162, no. 5, pp. 1773-1777, 2000.

[15] http://www.drugbank.ca/.

[16] R. Bone, M. Boyars, S. R. Braun et al., "In chronic obstructive pulmonary disease, a combination of ipratropium and albuterol is more effective than either agent alone: an 85-day multicenter trial," Chest, vol. 105, no. 5, pp. 1411-1419, 1994.

[17] A. Rossi, P. Kristufek, B. E. Levine et al., "Comparison of the efficacy, tolerability, and safety of formoterol dry powder and oral, slow-release theophylline in the treatment of COPD," Chest, vol. 121, no. 4, pp. 1058-1069, 2002.

[18] G. Boyd, A. H. Morice, J. C. Pounsford, M. Siebert, N. Peslis, and C. Crawford, "An evaluation of salmeterol in the treatment of chronic obstructive pulmonary disease (COPD)," European Respiratory Journal, vol. 10, no. 4, pp. 815-821, 1997.

[19] M. Campbell, A. Eliraz, G. Johansson et al., "Formoterol for maintenance and as-needed treatment of chronic obstructive pulmonary disease," Respiratory Medicine, vol. 99, no. 12, pp. 1511-1520, 2005.

[20] D. A. Mahler, J. F. Donohue, R. A. Barbee et al., "Efficacy of salmeterol xinafoate in the treatment of COPD," Chest, vol. 115, no. 4, pp. 957-965, 1999.

[21] R. Dahl, K. F. Chung, R. Buhl et al., "Efficacy of a new oncedaily long-acting inhaled $\beta 2$-agonist indacaterol versus twicedaily formoterol in COPD," Thorax, vol. 65, no. 6, pp. 473-479, 2010.

[22] P. J. Barnes, "The role of anticholinergics in chronic obstructive pulmonary disease," The American Journal of Medicine, vol. 117, pp. 24S-32S, 2004.

[23] A. M. Yohannes, T. G. Willgoss, and J. Vestbo, “Tiotropium for treatment of stable COPD: a meta-analysis of clinically relevant outcomes," Respiratory Care, vol. 56, no. 4, pp. 477-487, 2011.

[24] V. Brusasco, R. Hodder, M. Miravitlles, L. Korducki, L. Towse, and S. Kesten, "Health outcomes following treatment for six months with once daily tiotropium compared with twice daily salmeterol in patients with COPD," Thorax, vol. 58, no. 5, pp. 399-404, 2003.

[25] D. D. Briggs Jr., H. Covelli, R. Lapidus, S. Bhattycharya, S. Kesten, and C. Cassino, "Improved daytime spirometric efficacy of tiotropium compared with salmeterol in patients with COPD," Pulmonary Pharmacology and Therapeutics, vol. 18, no. 6, pp. 397-404, 2005. 
[26] J. A. Wedzicha, P. M. A. Calverley, T. A. Seemungal, G. Hagan, Z. Ansari, and R. A. Stockley, "The prevention of chronic obstructive pulmonary disease exacerbations by salmeterol/fluticasone propionate or tiotropium bromide," American Journal of Respiratory and Critical Care Medicine, vol. 177, no. 1, pp. 19-26, 2008.

[27] R. Casaburi, D. Kukafka, C. B. Cooper, T. J. Witek, and S. Kesten, "Improvement in exercise tolerance with the combination of tiotropium and pulmonary rehabilitation in patients with COPD," Chest, vol. 127, no. 3, pp. 809-817, 2005.

[28] S. Singh, Y. K. Loke, and C. D. Furberg, "Inhaled anticholinergics and risk of major adverse cardiovascular events in patients with chronic obstructive pulmonary disease: a systematic review and meta-analysis," Journal of the American Medical Association, vol. 300, no. 12, pp. 1439-1450, 2008.

[29] D. P. Tashkin, B. Celli, S. Senn et al., "A 4-year trial of tiotropium in chronic obstructive pulmonary disease," The New England Journal of Medicine, vol. 359, pp. 1543-1554, 2008.

[30] T. M. Michele, S. Pinheiro, and S. Iyasu, "The safety of tiotropium-the FDA's conclusions," The New England Journal of Medicine, vol. 363, no. 12, pp. 1097-1099, 2010.

[31] D. Auerbach, C. Hill, R. Baughman et al., "Routine nebulized ipratropium and albuterol together are better than either alone in COPD," Chest, vol. 112, no. 6, pp. 1514-1521, 1997.

[32] J. A. van Noord, J. L. Aumann, E. Janssens et al., "Comparison of tiotropium once daily, formoterol twice daily and both combined once daily in patients with COPD," European Respiratory Journal, vol. 26, no. 2, pp. 214-222, 2005.

[33] S. E. McKay, C. A. Howie, A. H. Thomson, B. Whiting, and G. J. Addis, "Value of theophylline treatment in patients handicapped by chronic obstructive lung disease," Thorax, vol. 48, no. 3, pp. 227-232, 1993.

[34] M. Aubier, "Respiratory muscle pharmacotherapy," European Respiratory Journal, vol. 7, pp. 592S-594S, 1989.

[35] Y. To, K. Ito, Y. Kizawa et al., "Targeting phosphoinositide-3kinase- $\delta$ with theophylline reverses corticosteroid insensitivity in chronic obstructive pulmonary disease," American Journal of Respiratory and Critical Care Medicine, vol. 182, no. 7, pp. 897904, 2010.

[36] Y. Zhou, X. Wang, X. Zeng et al., "Positive benefits of theophylline in a randomized, double-blind, parallel-group, placebo-controlled study of low-dose, slow-release theophylline in the treatment of COPD for 1 year," Respirology, vol. 11, no. 5, pp. 603-610, 2006.

[37] M. Cazzola and R. Dahl, "Inhaled combination therapy with long-acting $\beta_{2}$-agonists and corticosteroids in stable COPD," Chest, vol. 126, no. 1, pp. 220-237, 2004.

[38] P. M. Calverley, W. Boonsawat, Z. Cseke, N. Zhong, and S. Peterson, "Maintenance therapy with budesonide and formoterol in chronic obstructive pulmonary disease," European Respiratory Journal, vol. 22, no. 6, pp. 912-919, 2003.

[39] C. Crim, P. M. A. Calverley, J. A. Anderson et al., "Pneumonia risk in COPD patients receiving inhaled corticosteroids alone or in combination: TORCH study results," European Respiratory Journal, vol. 34, no. 3, pp. 641-647, 2009.

[40] D. Singh, J. Brooks, G. Hagan, A. Cahn, and B. J. O'Connor, "Superiority of "triple" therapy with salmeterol/fluticasone propionate and tiotropium bromide versus individual components in moderate to severe COPD," Thorax, vol. 63, no. 7, pp. 592-598, 2008.

[41] T. Welte, M. Miravitlles, P. Hernandez et al., "Efficacy and tolerability of budesonide/formoterol added to tiotropium in patients with chronic obstructive pulmonary disease," American Journal of Respiratory and Critical Care Medicine, vol. 180, no. 8, pp. 741-750, 2009.

[42] B. J. Lipworth, "Phosphodiesterase-4 inhibitors for asthma and chronic obstructive pulmonary disease," The Lancet, vol. 365, no. 9454, pp. 167-175, 2005.

[43] D. Price, A. Chisholm, D. Ryan, A. Crockett, and R. Jones, "The use of roflumilast in COPD: a primary care perspective," Primary Care Respiratory Journal, vol. 19, no. 4, pp. 342-351, 2010.

[44] P. M. Calverley, K. F. Rabe, U. M. Goehring, S. Kristiansen, L. M. Fabbri, and F. J. Martinez, "Roflumilast in symptomatic chronic obstructive pulmonary disease: two randomised clinical trials," The Lancet, vol. 374, no. 9691, pp. 685-694, 2009.

[45] K. F. Rabe, E. D. Bateman, D. O’Donnell, S. Witte, D. Bredenbröker, and T. D. Bethke, "Roflumilast-an oral antiinflammatory treatment for chronic obstructive pulmonary disease: a randomised controlled trial," The Lancet, vol. 366, no. 9485, pp. 563-571, 2005.

[46] C. H. Compton, J. Gubb, R. Nieman et al., "Cilomilast, a selective phosphodiesterase- 4 inhibitor for treatment of patients with chronic obstructive pulmonary disease: a randomised, dose-ranging study," The Lancet, vol. 358, no. 9278, pp. 265-270, 2001.

[47] M. A. Giembycz, "An update and appraisal of the cilomilast Phase III clinical development programme for chronic obstructive pulmonary disease," British Journal of Clinical Pharmacology, vol. 62, no. 2, pp. 138-152, 2006.

[48] M. A. Giembycz, "Cilomilast: a second generation phosphodiesterase 4 inhibitor for asthma and chronic obstructive pulmonary disease," Expert Opinion on Investigational Drugs, vol. 10, no. 7, pp. 1361-1379, 2001.

[49] J. R. Jacobsen, “Third-generation long-acting $\beta_{2}$-adrenoceptor agonists: medicinal chemistry strategies employed in the identification of once-daily inhaled $\beta_{2}$-adrenoceptor agonists," Future Medicinal Chemistry, vol. 3, no. 13, pp. 1607-1622, 2011.

[50] D. P. Tashkin and L. M. Fabbri, "Long-acting beta-agonists in the management of chronic obstructive pulmonary disease: current and future agents," Respiratory Research, vol. 11, article 149, 2010.

[51] D. L. Kelleher, R. S. Mehta, B. M. Jean-Francois et al., "Safety, tolerability, pharmacodynamics and pharmacokinetics of umeclidinium and vilanterol alone and in combination: a randomized crossover trial," PLoS One, vol. 7, Article ID e50716, 2012.

[52] N. A. Hanania, G. Feldman, W. Zachgo et al., "The efficacy and safety of the novel long-acting $\beta_{2}$ agonist vilanterol in patients with COPD: a randomized placebo-controlled trial," Chest, vol. 142, pp. 119-127, 2012.

[53] G. Feldman, R. R. Walker, J. Brooks, R. Mehta, and G. Crater, "28-Day safety and tolerability of umeclidinium in combination with vilanterol in COPD: a randomized placebo-controlled trial," Pulmonary Pharmacology \& Therapeutics, vol. 25, pp. 465-471, 2012.

[54] W. W. Busse, E. R. Bleecker, E. D. Bateman et al., "Fluticasone furoate demonstrates efficacy in patients with asthma symptomatic on medium doses of inhaled corticosteroid therapy: an 8-week, randomised, placebo-controlled trial," Thorax, vol. 67, pp. 35-41, 2012.

[55] J. A. van Noord, J. J. Smeets, B. M. Drenth et al., "24-hour bronchodilation following a single dose of the novel $\beta_{2}$-agonist 
olodaterol in COPD," Pulmonary Pharmacology \& Therapeutics, vol. 24, pp. 666-672, 2011.

[56] V. Gupta and D. Singh, "Aclidinium bromide for the treatment of chronic obstructive pulmonary disease," Expert Review of Respiratory Medicine, vol. 6, pp. 581-588, 2012.

[57] M. W. Sims and R. A. Panettieri Jr., "Profile of aclidinium bromide in the treatment of chronic obstructive pulmonary disease," International Journal of Chronic Obstructive Pulmonary Disease, vol. 6, pp. 457-466, 2011.

[58] P. Chanez, P. S. Burge, R. Dahl et al., "Aclidinium bromide provides long-acting bronchodilation in patients with COPD," Pulmonary Pharmacology and Therapeutics, vol. 23, no. 1, pp. 15-21, 2010.

[59] P. W. Jones, D. Singh, E. D. Bateman et al., "Efficacy and safety of twice-daily aclidinium bromide in COPD patients: the ATTAIN study," European Respiratory Journal, vol. 40, pp. 830-836, 2012.

[60] R. Fuhr, H. Magnussen, K. Sarem et al., "Efficacy of aclidinium bromide $400 \mu \mathrm{g}$ twice daily compared with placebo and tiotropium in patients with moderate to severe COPD," Chest, vol. 141, no. 3, pp. 745-752, 2012.

[61] F. Maltais, B. Celli, R. Casaburi et al., "Aclidinium bromide improves exercise endurance and lung hyperinflation in patients with moderate to severe COPD," Respiratory Medicine, vol. 105, no. 4, pp. 580-587, 2011. 


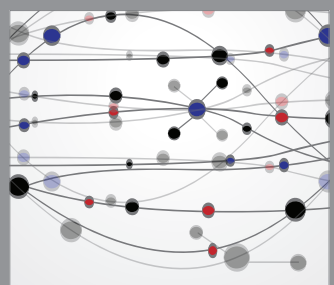

The Scientific World Journal
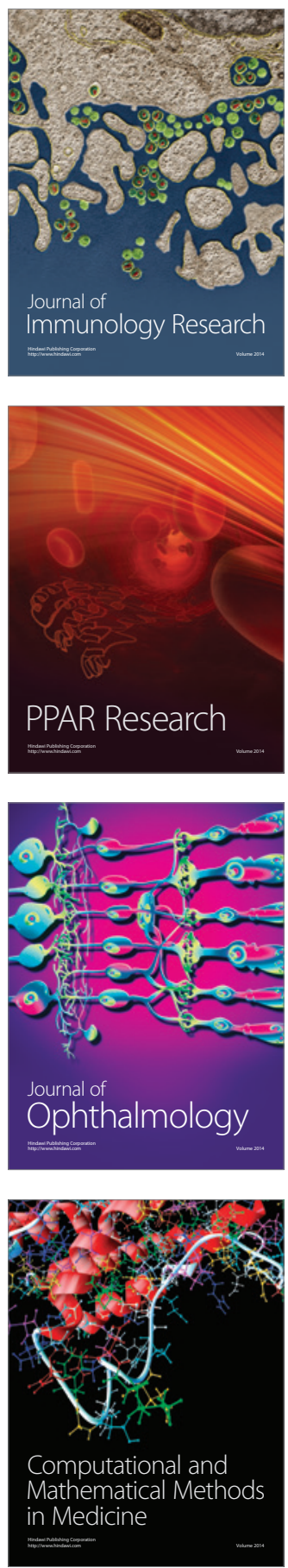

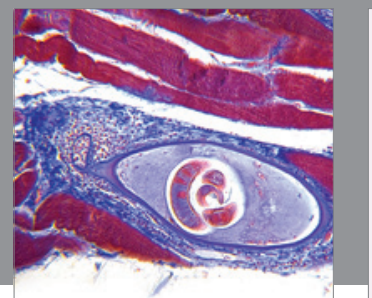

Gastroenterology

Research and Practice
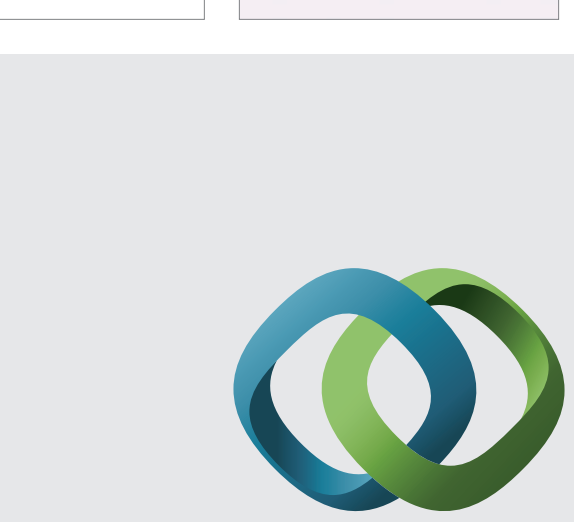

\section{Hindawi}

Submit your manuscripts at

http://www.hindawi.com
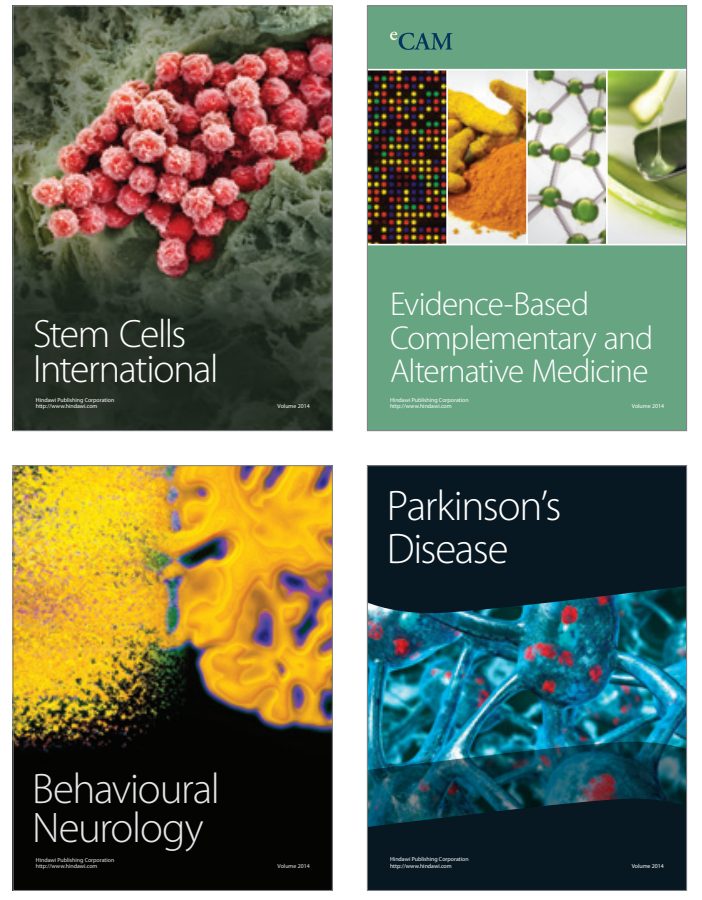
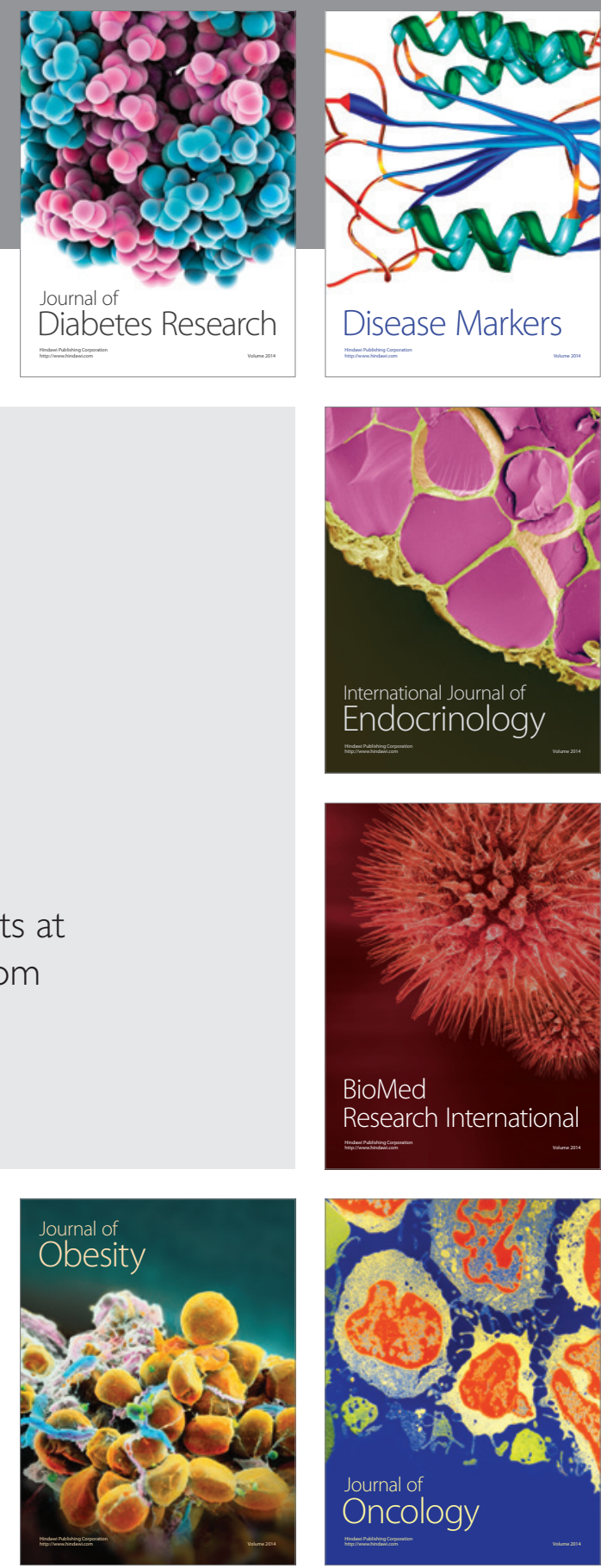

Disease Markers
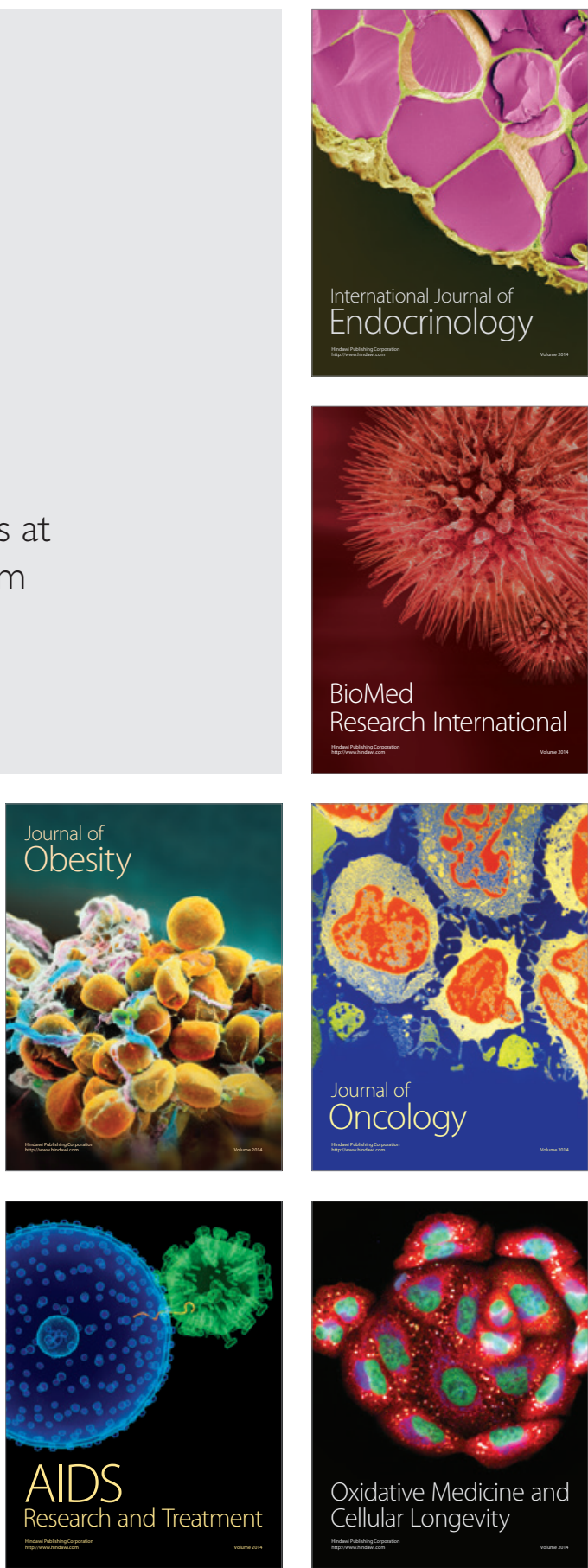